\title{
Spiritual Domain: The Domain of Learning for Cultivating a Spiritually Intelligent Culture
}

\author{
Dr. Prasanth Mathew \\ P.K.M. College of Education, Kannur University, Kannur, Kerala, India \\ Bethlehem Educational Research Foundation, Kerala, India \\ Mrs. P. Teena George \\ Bethlehem Educational Research Foundation, Kerala, India
}

\begin{abstract}
A disintegrating morale is a distinguishing feature of the modern culture. A cultural shift from a spiritually dumb culture to a spiritually intelligent culture is imperative for sustained excellence. The transformative principles of spiritual intelligence enable the lasting shift from motivational shift to behavioral shift to cultural shift. The paper focuses on the "Spiritual Domain" of learning in education in accomplishing the cultural shift, whereby teachers play the crucial role of "culture brokering" by enabling pupils to cross the cultural borders. The paper highlights the educational experiments conducted by the researchers at different levels of education with emphasis on the "spiritual domain of learning". The paper also highlights the objectives of the spiritual domain of learning and three different models of learning based on these objectives.
\end{abstract}

Keywords: Spiritual Domain of learning, scientific sensitivity, spiritual Intelligence

\section{Introduction}

The world today presents a culture of corporeal concern with little regard for ethical, moral, and spiritual values that enrich the deepest yearning of the human spirit. The materialistic existence of man in a material world posits challenging state of affairs day by day, hour by hour, and minute by minute whereby right choices at the right moment are to be made between hidden viciousness and apparent virtues. The degenerating and disintegrating culture encourages outright denial of rectitude, righteousness, and sincerity for power and affluence. The paths to moral degradation are highly persuasive, easy, and convenient in contrast to the highly challenging perplex and adverse pathways to propriety and virtues. In the face of such challenges in the world today, it is highly indispensible to develop virtues like magnanimity, selfless love, humility, wisdom, sacrifice, and perfection that would aid to withstand and overcome the challenges of the temporal world. Ways and means to lift human beings from sheer materialistic existence to a higher level of spiritual well being are inevitable for a sustainable future.

Man has a longing for something towards which he can aspire, for something that takes him beyond himself and the present moment, for something that gives him and his actions a sense of worth. Human beings

Dr. Prasanth Mathew, Assistant Professor in Physical Science, M.Sc., M.Ed, Ph.D., P.K.M. College of Education, Bethlehem Educational Research Foundation.

Mrs. P. Teena George, Chairman \& Managing Trustee, M.A., B.Ed., Bethlehem Educational Research Foundation. 
are essentially spiritual creatures because we are driven by a need to ask "fundamental" or "ultimate" questions. Why was I born? What is the meaning of my life? Why should I go on when I am tired or depressed, or feel beaten? What makes it all worthwhile?

Spirituality is connected to what is discussed as the life force, God, a higher power or purpose, Great Mystery (Tisdell, 2003). It helps individuals to live at peace with themselves, to love God and their neighbor, and to live in harmony with the environment (John, 2011). It gives a sense of wholeness and leads to Spiritual Well Being (SWB) which is defined as "the affirmation of life in a relationship with God, self, community and environment that nurtures and celebrates wholeness" (NICA, 1975).

Spirituality can be recognized as both a way of perceiving and a way of acting. As a way of perceiving, it opens our eyes to the "moreness" of our lives. We are always "more" in the sense that we possess the possibility of reaching beyond our present state — of transcending who and what we currently are. And we are always "more" in the sense that we do not dwell in the world alone; we cannot be human beings without others. The second aspect leads us to the action of spirituality - becoming aware of our oneness with others and the world, then acting on this perception.

\section{Spiritually Intelligent Culture}

At the beginning of the 20th century as psychologists discovered ways and means to measure intelligence, Aristotle's definition of man as a rational animal developed in to an obsession with IQ (Intelligence Quotient). In the middle of 1990s, Daniel Goleman popularized research in to emotional intelligence, EQ (Emotional Quotient), pointing out that EQ is the basic requirement for the appropriate use of IQ. Now there is enough collective evidence from Psychology, Neurology, Anthropology, and Cognitive Science to show us that there is a third Q, SQ, or "Spiritual Intelligence". Zohar and Marshall (2000) made the first attempt to find out the notion of Spiritual Intelligence. Later many have made significant contributions to the field of Spiritual Intelligence. Zohar and Marshall (2000) define spiritual intelligence as,

The intelligence with which we address and solve problems of meaning and value, the intelligence with which we can place our actions and our lives in a wider, richer, meaning giving context, the intelligence with which we can assess that one course of action or one life-path is more meaningful than another. (p. 3)

Spiritual capital is considered as the byproduct of Spiritual Intelligence. Spiritual capital is the most recent form of capital which describes value available to the society. According to Zohar and Marshall (2004) Spiritual Intelligence's sense of meaning, values, and purpose generates spiritual capital. Spiritual capital's wealth of meaning, values, and higher motivation are necessary to sustainable capitalism and a sustainable society. We build spiritual capital by building ourselves. "Building ourselves" means to grow as human beings; to engage in reflection and activities that put us in touch with the deeper core of our humanity. Organizations rich in spiritual capital are not just sustainable, they are evolutionary. People, organizations, and cultures that have spiritual capital will be more sustainable because they will have developed qualities that include wider, values-based vision, global concern and compassion, long-term thinking, spontaneity (and hence flexibility), an ability to act from their own deepest convictions, an ability to thrive on diversity, and an ability to learn from and make positive use of adversity.

The 12 dynamic process or the qualities and principles of transformation or the behavioral and cultural indicators of our spiritual intelligence, viz., Self-awareness, Spontaneity, Being vision and value led, Holism, 
Compassion, Celebration of diversity, Field independence, Tendency to ask fundamental why questions, Ability to reframe, Positive use of adversity, Humility, and Sense of vocation provide an energy input that enables us to shift our individual behavior (Zohar \& Marshall, 2004). A critical mass of individuals using their spiritual intelligence to act from higher motivations, can shift the dominant features of a whole culture, be it that of a family, a community, an organization, or of a whole global culture.

\section{Reorienting Education for Building up Spiritually Intelligent Culture}

Human being's IQ is pretty well steady throughout life, barring illness or damage. But EQ, or emotional intelligence, can be learned, nurtured, and improved. And all human beings are born with a potential for high SQ. But our spiritually dumb culture and educational system, and our often spiritually deadening work patterns and pressures, reduce our capacity to practice our SQ. Like EQ, SQ must be nurtured. It can be relearned, and it can be improved. However, most schooling ignores the spiritual nature of human beings, and the techno rational reigns supreme as both students and knowledge are sorted and slotted in the most efficient manner. The school's spiritual mission as a work of transcending the status quo is forgotten or ignored. In the light of the spiritual dumbness of modern man, educators have a crucial role to play as "culture brokers". Cultural shifts would be possible if educators bear the responsibility of culture brokering by enabling pupils to cross the cultural borders, from the spiritually dumb to the spiritually intelligent culture.

\section{The Spiritual Domain in Education}

Considering the flaws of the present education system, especially in its failure to adopt measures and techniques to foster the spiritual dimension in pupils, the researchers founded the Bethlehem Educational Research Foundation (Presently, BERF is an institutional member of World Council for Curriculum and Instruction; a non-governmental organization of the United Nations in consultative status with the Economic and Social Council) in June 2001 with the motto "Education: The means to divinity". It is a non-governmental, nonprofit Educational Organization of a team of educational researchers. The organization is an offshoot of the researchers' genuine desire to cultivate a "spiritually intelligent culture" through education in the light of the "spiritually dumb culture" exhibited by the modern society. The researchers of Bethlehem Educational Research Foundation (BERF) have conducted various educational experiments at different levels of education namely, the pre-primary, primary, and secondary levels.

\section{Educational Experiments}

Bethlehem Educational Research Foundation started a pre-primary school (Bethlehem Nursery) in June 2001, at Bethlehem Centre, Kidangoor, Kottayam, Kerala with the aim of laying a basic foundation for developing a divine vision, propriety, and civility in children. The teachings of Christ which breaks the barriers of religion and bears universal significance have been accepted as the source of guidance in every activity of the pre-primary school.

For students of the primary and secondary levels of Malayalam medium schools the Bethlehem Educational Research Foundation conducted a couple of educational experiments for teaching the English language using "spiritual" medium, viz., lives of saints and Biblical stories as learning materials. The first experiment was conducted during summer vacation at Bethlehem centre from April 21st to May 11th in the year 2003. Around 80 students took part in the programme. Each day the students spent four hours at the centre. 
One hour was devoted for prayers and reflections, two hours for developing the listening and reading skills and one hour for creative activities. The second experiment was conducted as a camp of 10 days at the centre from April 11th to April 21st in the year 2004 for the same group of students with the objective of helping them to experience the principles of learning to learn, learning to live together, learning to do, and learning to be. Learning materials promoting values of universal significance like obedience, service, love, importance of work, poverty, divine providence, moderate use of tongue, prayer, wisdom were chosen for equipping children with greater competency of their speaking and writing skills in English.

\section{Bethlehem Oratory: A Family Based System of Education}

Keeping in view the significance of the role of family in fostering spiritual intelligence of children, BERF initiated an experimental system of education in June 2006 with the name "Bethlehem Oratory" for children (K-12). Bethlehem Oratory is a family based system of education which functions as learning communities of families who share the view of cultivating spiritually intelligent culture in children by enabling them to realize the divinity in oneself, in nature and others; by nurturing virtues in them; and by generating in them a feeling of sensitivity to nature and sensitivity to the feelings of others. They follow a way of life based on Christian principles characterized by firm belief in the divine presence and providence in every activity of their life. As these learning communities of families stay at different parts of India children from these families, along with their parents gather together occasionally at different centres, learn together, discuss their educational issues, arrange camps, retreats, workshops, etc.

At present each community of families following this system of education has a minimum of three families staying nearby. After attending the Holy Mass together, they engage in the domestic works in their respective families after which they gather together at the centre for formal learning at 10 am up to $4 \mathrm{pm}$. The children are grouped according to their age levels. Each group is dealt with by their respective teachers/qualified parents. In the curriculum transaction learning experiences are provided giving emphasis on the Spiritual Domain of learning.

Each family of Bethlehem Oratory, follows the strategy of family sat sang which is a gathering of the members of the family - grandparents, parents, and children - in the evening. They spend about one hour together to have an open sharing of their experiences, their ideas on various issues; offer healthy suggestions for personal improvement, etc. It is conducted as a continuous, daily activity of a single family; as a weekly gathering of a community of families; and as monthly and annual gatherings of communities of families where children are given opportunities to present their talents in various fields; to express their views on important life related issues, etc.

\section{Spiritual Domain of Learning}

The educational experiments conducted by the Bethlehem Educational Research Foundation highlighted the possibility of a new domain in curricular transaction namely the "Spiritual Domain" (Mathew, 2008). Spiritual domain is the domain of learning that tends to foster the spiritual intelligence of learners along with their cognitive, affective, and psychomotor competencies. With the intention of fostering the spiritual intelligence of learners, the researchers are in the process of developing a curriculum of learning based on Spiritual Domain in education from the Primary to the Higher Secondary level. The process includes developing taxonomy of educational objectives of Spiritual Domain in different subjects; the various learning experiences to be provided for the attainment of these objectives; and the various assessment procedures to be 
made to check the attainment of the objectives.

\section{Spiritual Domain: Objectives of Learning}

The general objectives of learning and the learning outcomes that come under the Spiritual Domain are presented in Table 1.

Table 1

Spiritual Domain: Objectives of Learning

\begin{tabular}{lll}
\hline Objectives & Learning outcomes \\
\hline $\begin{array}{l}\text { Realizing the divine nature (perfection) behind } \\
\text { creation }\end{array}$ & $\begin{array}{l}\text { Developing humbleness of spirit in the learners } \\
\text { (an awareness of our own vulnerability to error and openness to } \\
\text { surprises and new perspectives) }\end{array}$ \\
$\begin{array}{l}\text { Realizing the interconnectedness between nature } \\
\text { and man in creation. }\end{array}$ & $\begin{array}{l}\text { (a disposition to think critically and act responsibly in relation to the } \\
\text { ways in which science affects people's lives) } \\
\text { Developing social sensitivity in the learners } \\
\text { (an awareness of social issues, feelings, needs and problems of others } \\
\text { and efforts to solve the problems) }\end{array}$ \\
Realizing the interconnectedness among human \\
beings.
\end{tabular}$\quad$\begin{tabular}{l} 
Practicing virtues/values in personal life \\
\hline
\end{tabular}

\section{Spiritual Domain: Models of Learning}

In order to provide learning experiences based on the objectives of the Spiritual Domain of learning, various pedagogic models of learning have been designed:

\section{Model I: Creative Learning Model-Constants of Nature}

Creative Learning Model based on the constants of nature, designed for learning the concepts discovered by scientists is presented in Table 2 .

Table 2

Model I: Creative Learning Model-Constants of Nature

\begin{tabular}{ll}
\hline Objectives/Focus & Realizing the divine nature behind the creation \\
\hline Syntax & \\
\hline Phase 1 & Understanding the Scientific concept/existing reality \\
Phase 2 & Thinking creatively on a condition contrary to the existing reality \\
Phase 3 & Comparing the existing reality with the creative expression \\
Phase 4 & Reflecting on the divine nature (perfection) behind the creation \\
Learning outcome & Developing humbleness of spirit in the learners \\
\hline
\end{tabular}

\section{Description of the Model}

The first phase comprises of conceptual understanding through the process of enquiry and investigation. The second phase includes providing tasks on a condition contrary to the existing reality, thereby making the learners think creatively and arriving at creative expressions like creative writings, pictorial representations etc. In the third phase the existing reality is compared with the creative expression. Finally the learners reflect on the precision, perfection and wholeness of creation behind "the constants of nature".

\section{Learning Task}

While learning the scientific concepts:

Water has its maximum density at $4^{\circ} \mathrm{C}$ (liquid state).

Ice floats in water due to this anomalous nature which allows fish and other life to survive in the cold climates. 
Learners think creatively on conditions like:

What would happen to the world if water had its maximum density at $0{ }^{\circ} \mathrm{C}$ (solid state)?

\section{Model II: Creative Learning Model-Scientific Inventions}

The model designed for learning the Scientific issues (social, moral, environmental, and health issues) that emerged as the aftermath of various scientific inventions is presented in Table 3.

Table 3

Model II: Creative Learning Model_Scientific Inventions

\begin{tabular}{ll}
\hline Objectives/Focus & Realizing interconnectedness between nature and man in creation \\
\hline Syntax & Understanding the Scientific issue/existing reality \\
\hline Phase 1 & Thinking creatively on a condition (based on the aftermath of scientific inventions)contrary to the \\
Phase 2 & Cxisting reality \\
Phase 3 & Reflecting on the interconnectedness between nature and man in creation \\
Phase 4 & Developing scientific sensitivity in the learners \\
Learning outcomes &
\end{tabular}

\section{Description of the Model}

The first phase comprises of understanding of the issue. The second phase includes providing tasks focusing on the aftermath of various inventions brought forth by modern science thereby making the learners think creatively and arriving at creative expressions like creative writings, pictorial representations, etc. In the third phase, the existing reality is compared with the creative expression. In the final phase, the learners reflect on the interconnectedness between nature and man established by the divine hand in creation.

The recognition and realization of such consequences would lead to scientific sensitivity which incorporates the spirit of care, compassion, planetary cooperation, reciprocity, and responsiveness.

\section{Learning Tasks}

While learning the environmental issues: deforestation, water pollution, air pollution, learners think creatively on conditions like:

What would happen if:

There were no plants?

There was no water to drink?

There were frequent acid rains?

\section{Model III: Virtue/Value Integration Model}

The model designed for nurturing virtues/values in the learners while learning scientific concepts and issues is presented in Table 4.

Table 4

Model III: Virtue/Value Integration Model

\begin{tabular}{ll}
\hline Objectives/Focus & Nurturing of Virtues/Values \\
\hline Syntax & \\
\hline Phase 1 & Understanding the Scientific concept/issues \\
Phase 2 & Identifying the Spiritual Theme related to the scientific concept \\
Phase 3 & Relating the scientific concept to the spiritual theme \\
Phase 4 & Reflecting on the importance of personalization of the virtue/value \\
Learning outcomes & Practicing virtues/values in personal life \\
\hline
\end{tabular}




\section{Description of the Model}

The first phase comprises of understanding of the scientific concept/issue. In the second phase, the spiritual theme related to the concept is identified. In the third phase the concept is related to the spiritual theme. In the final phase, the learners reflect on the importance of personalization of the value.

\section{Learning Task}

While learning the scientific concept (secondary level) of capillary rise which states: "As the radius of the capillary tube decreases, the capillary rise increases", learners identify the spiritual theme related to the scientific concept:

"For all who exalt themselves will be humbled, but all who humble themselves will be exalted" (Biblical theme).

Learners reflect on the importance of the value of humility in their personal lives.

\section{Conclusion}

The spiritual stuntedness of man has led to a spiritually dumb culture. The creation of a spiritually intelligent culture is the need of the time. Education must bring out spiritually intelligent individuals who can together make a cultural shift possible. An urgency of fostering the spiritual dimension of man which can be achieved through education by focusing on the spiritual domain of learning along with the competencies in cognitive, emotional, and psychomotor realms calls for a shift in the aims, modes, and methods of curricular transaction which would nurture the spiritual intelligence of pupils. The transition from a spiritually dumb culture to a spiritually intelligent culture can be materialized through the educative process characterized by a "way of life" which enables reverence for the sacred; sensitivity to nature and sensitivity to the feelings of others; a "way of life" which enables the recognition and contact with one's "deep self", the source of the vital energy for fulfilling the fundamental purposes of life. Spiritually intelligent teachers must take up their role as "culture brokers" to make cultural shifts possible.

\section{References}

John, F. (2011). The four domains model: Connecting spirituality, health and well-being. Religions, 2(1), 17-28.

Mathew, P. (2008). Education: The means to divinity. In Building a Culture of Peace for a Civil Society-Proceedings of the 12th World Conference on Education, Manila, Philippines.

National Interfaith Coalition on Aging (NICA). (1975). Spiritual well-being: A definition. Athens, GA, USA: NICA.

Tisdell, E. (2003). Exploring spirituality and culture in adult and higher education. San Francisco: Jossey-Bass.

Zohar, D. (2004). Spiritual capital: Wealth we can live by. London: Bloomsbury.

Zohar, D., \& Marshall, I. (2000). SQ, Spiritual Intelligence: The ultimate intelligence. London: Bloomsbury. 